\title{
Neolithic settlement in Bylany: taking a new look at old digs
}

\author{
P. KvČtina*, M. KonČelová, H. Brzobohatá, R. Čumberová, J. ČídkČ, I. PavlČ
}

Institute of Archaeology of the Academy of Sciences of the Czech Republic, Prague, Letenská 4, 11801 Prague, Czech Republic (kvetina, koncelova, brzobohata, sumberova, ridky, pavlu)@arup.cas.cz

KEY WORDS: Virtual museum, Archaeology, Neolithic settlement, Bylany (Czech Republic), Pottery, Lithics, GIS, 3D optical scanning

\begin{abstract}
:
The aim of the project is to apply 3D scanning technology to create a virtual museum providing a picture of the Neolithic culture, based on the example of the settlement in Bylany (Czech Republic), dating from the 6th -5 th millennium B.C. The main parameter of the applied research is to set up a methodology for recording and presenting archaeological finds digitally. The basic technology is optical 3D scanning of artefacts that exactly reflect the 3D surface geometry and will bring new presentation possibilities. Acquired digital records can also serve as well as for research and educational purposes on all academic levels. The project's most important output consists in a virtual museum on the web of the Neolithic settlement area. Moreover, the open library of 3D scans will integrate a thematic GIS map of the Bylany site and its virtual model showing different forms of the immovable heritage (i.e., houses, circle enclosures and villages).
\end{abstract}

\section{INTRODUCTION}

The given issues of 3D imaging and virtual modelling of monuments, especially movable ones, can be considered on two levels. The first is the field of making the cultural heritage more accessible and popular in which the method of $3 \mathrm{D}$ visualisation is used to make the presentations more attractive (Bruno et al., 2010). This also happens within exhibitions in traditional museums. Nevertheless, Internet exhibitions are the home ground of virtual 3D visualisation and recently these exhibitions have been spreading very rapidly and becoming an inseparable part of museums and other cultural institutions (Grant et al., 2008).

The other level using 3D projection techniques is the effort to perform the shape analyses of an object through the parameters of its virtual model. These methods of scanning and imaging have great analytical potential especially in those fields which are based on material sources. Three-dimensional scanning and geometric morphometrics already are a part of the standard portfolio of methods used in disciplines related to archaeology, such as anthropology (physical and paleoanthropology) (Urbanová and Králík, 2009). Archaeology itself is a field, where laboratory scanning and consequent analysis of data are just beginning, as documented by the published data of focused works (e. g., Saragusti et al., 2005; Archer and Braun, 2010; Bruno et al., 2010).

The objectives of these analyses usually focus on the unbiased assessment of the shape parameters of artefacts based on the image and statistical data extracted from polygonal models. Such approaches are collectively called geometrical morphometry. The published examples show that not only the issues of artefact typology and chronology, formal variability of style and technological varieties, but also functions of the studied objects can be solved in this way. The methods of 3D scanning and modern morphometry can be applied to the whole variety of artefacts from ceramics (Gilboa et al., 2004; Saragusti et al., 2005) to chipped stones (Archer and Braun 2010; Buchanan and Collard 2010; Lycett et al. 2010). A brand new trend within virtual 3D visualization is sharing databases of models of artefacts on the Internet. The access and potential for studying virtual models thus often replace the direct manipulation with archaeological findings, which are often difficult to reach. This significantly contributes to the process of learning about the past and also improves the prospects for the protection of these objects as such.

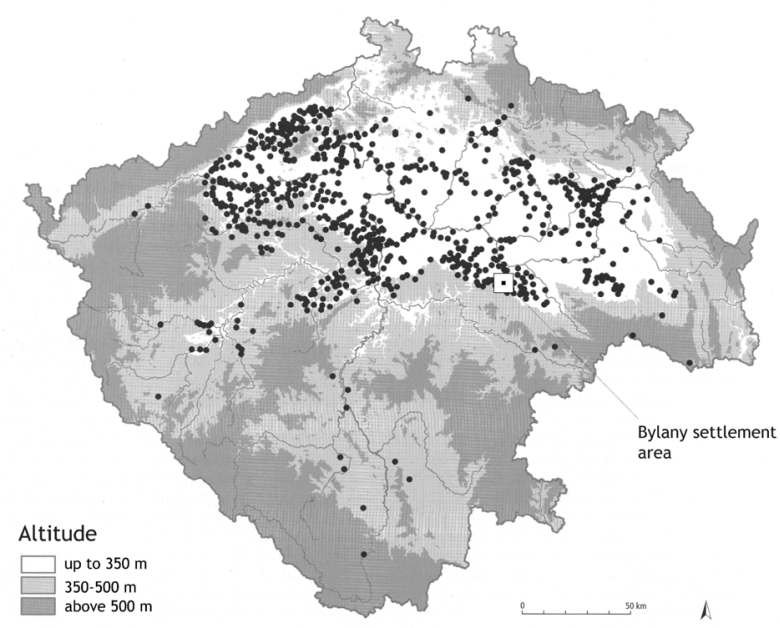

Figure 1: Bylany location map within Early Neolithic (LBK) settlement area in Bohemia

\subsection{Bylany settlement}

The aim of the project was to use the technology of 3D scanning to create a virtual museum which would present the picture of Neolithic culture in our territory as an example of a large settlement in Bylany near Kutná Hora. This locality is of global importance and the information provided by a long-term research on the spot, in fact, is basic knowledge about the world where the first farmers lived in Central Europe (Figure 1). The field project in Bylany was begun in 1953 and its goal was to completely excavate the settlement area from the Early Neolithic period $(5500-5000$ BC, Linear Pottery culture or LBK). During a period of 15 years, a total of seven ha $(70,000$ $\mathrm{mC}$, which is approximately seven football fields) was excavated, dating to the Early but also subsequent periods of the Neolithic. A total of 1,045 archaeological features and 144 more 
or less reasonably preserved ground plans of long houses were also studied. Archaeological finds make up a large assemblage of artefacts that includes pottery fragments, chipped stone, polished stone (axes and adzes), whetstones (abrading, smoothing, polishing tools), manos and metates (grinding slabs and querns). The most significant in terms of the chronology is the assemblage of pottery finds containing more than 76,000 fragments. In light of the fact that the archaeological monuments from this locality are not and have never been accessible to the public, this virtual exhibition will be the first complete presentation of the collection.

\section{METHOD}

The specific purpose of the project is the creation of a methodology for registration, preservation and presentation of archaeological findings in a digital form. The basic technology is optical 3D scanning of artefacts whose advantage is the ability to capture an absolutely faithful three-dimensional model of an object. This creates new barrier-free options for the presentation of both movable and immovable finds and also multiplies the potential of their presentation in case the original is destroyed. In the light of recent global experience this, unfortunately, is quite a real danger. (For example, The National Museum of Iraq destroyed by war in 2003 and the centres of cities in Central Europe hit by catastrophic floods in 2002.) Methodologically, the project will be realised on three levels:

a) The creation of a digitising laboratory, where the originals of archaeological finds will be transferred into a digital form. This will be realised by a 3D optical scanner Breuckmann SmartScan 3D-duo with accessories and corresponding software equipment. A web database will be created to secure the optimal course of work and individual models will be put into this database. At the same time a SW interface will be developed to run an online accessible 3D archaeological virtual museum with a wide range for users' choice of views and options of virtual manipulation with the object.

b) To make the presentation more illustrative, the museum will include specialised maps in GIS format, which will be made on the basis of field documentation of research. All the data will be publishable on the Internet through the specialised software of the Esri-Arc GIS Server 10 Workgroup, which will require no specific installations by the user/visitor to the museum.

c) At the same time, 3D virtual reconstruction of the Neolithic settlement and chosen structures (such as long houses and circle enclosures) will be created. These targets will be met through specialised software, which will enable rebuilding the original shape of the countryside on the basis of preserved field situations. This will provide a picture of a lively socio-cultural landscape. The final image will also be presented in site on several transparent boards which provide an observer with a precise picture of what the settlements of the area's first farmers actually looked like.

So-called "cloud computing" is intended as the final methodological solution for the web museum. This is a very progressive method of storage and making access to specific digital data, which are located in the data centre on the server and can be used through common web browsers. No installation of specialised licensed programmes by the end users is required.

\subsection{Acquisition of 3D models of artefacts.}

The method of choice is the acquisition of shape and colour information by optical scanning and using the scanner smart SCAN-3D (Breuckmann, GmbH). This modular topometric system works on the basis of a fringe projection of sequences of stripes on a physical model and recording the modified samples with a digital camera with high definition (5 MPx). Individual scans depicting the surface of the object from various points of view are subsequently merged into a final data object which defines both complex geometry and the texture of the scanned artefact. High accuracy of scanning artefacts (which are variable in terms of size) is made possible by the use of three additional measuring ranges for three fields of view from 60 to $300 \mathrm{mms}$ (FOV S060, FOV M125, FOV M300). The system includes programme equipment (OPTOCAT SW) which ensures the service of the digitising system during the process of scanning, automatic merging of individual scans and export of scans to various data formats. Another fractional task is the reducing the size of the file into a small fraction of its original size for the purposes of the web presentation. That means the objects which have not been displayed yet will be opened up to all interested people, including specialists. Specialists will be able to download polygonal models in their original (high) definition and consequently analyse them with any conventional methods including progressive approaches of geometric morphometry (Figure 2).
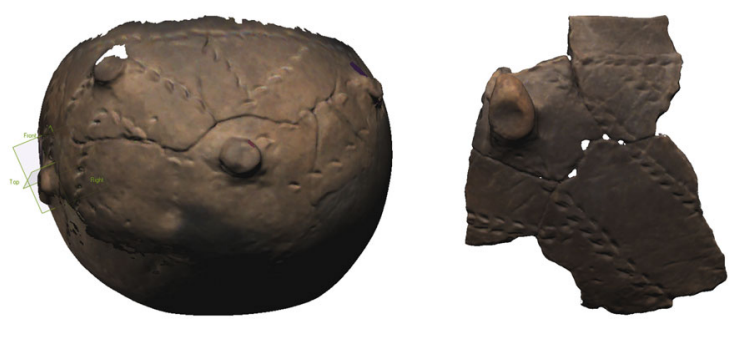

Figure 2: 3D optical scan of LBK vessel.

\subsection{Presentation of 3D models.}

Final 3D models will be published on the web through the RDV Civil 3D programme and a built-in visualising plug-in directly in the web browser and it will be unnecessary for users to install other software. The virtual museum will be activated on the already existing and established domain, www.bylany.com. The graphic environment of this page will be transformed for the needs of the presentation of $3 \mathrm{D}$ models and interactive browsing.

\subsection{GIS reconstruction map.}

The original map documentation of the archaeological excavations in Bylany was converted into a vector digital form. The resulting data is saved in a SHP format with the setup of geographical coordinates for the national grid S-JTSK (eastnorth). The SHP format is primarily intended for GIS software by the Esri Company, but can also be regularly used in other GIS programmes. The GIS system covers the complete area of the Bylany project and its individual components are adjoined both to the original documentation of field research and to the archaeological interpretation (Figure 3). Just this level of the reconstruction will become a part of the virtual museum. The relationship of various immovable monuments (houses, sacral circle enclosures or the development of the settlement) to each other and to the environment will be made clear in this form. While the current map of the Neolithic settlement in Bylany, realised in the ArcGIS environment, works regularly in $2 \mathrm{D}$, the new virtual version will be three-dimensional. Therefore, a system based on Esri - ArcGIS Server 10 Workgroup level platform will have to be created, which will interactively cooperate at the same time with Autodesk and Google 
SketchUp formats. The final system should facilitate the complex web administration of GIS, data, editing maps and be an easy way to publish maps on the Internet. The given programme will be included in the web museum and work as an interactive browser.

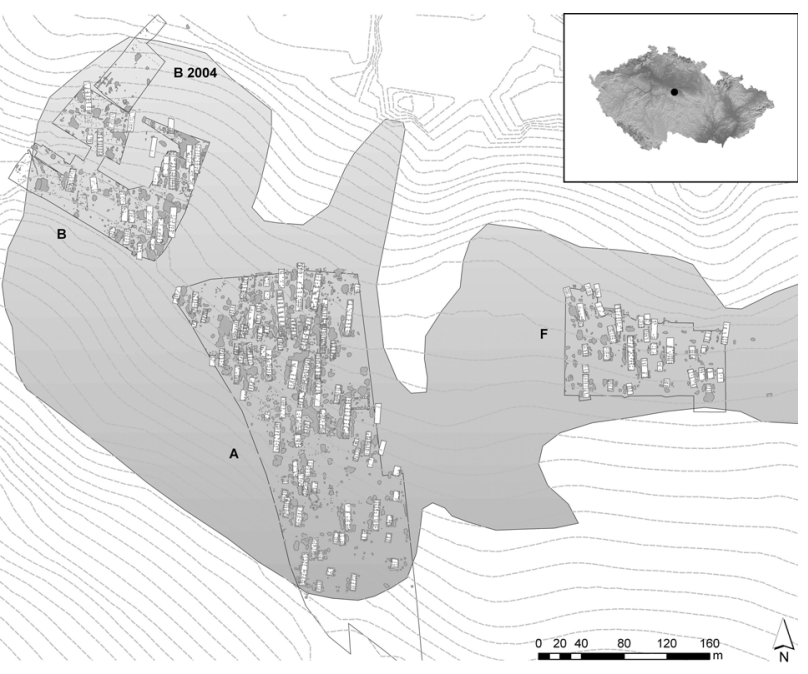

Figure 3: The status of archaeological excavations of the Bylany 1 area. The grey area indicates the total area of 21 ha inhabited during the Early Neolithic period.

2.4. Visualisation of $3 \mathrm{D}$ situational reconstructions of archaeological features.

The map part will also include a virtual tour around the Neolithic landscape. It will be based on the digital documentation of the geo-relief and archaeological findings included in the 3D GIS project and, moreover, it will add reconstructions to the map. These will have the form of real mo-
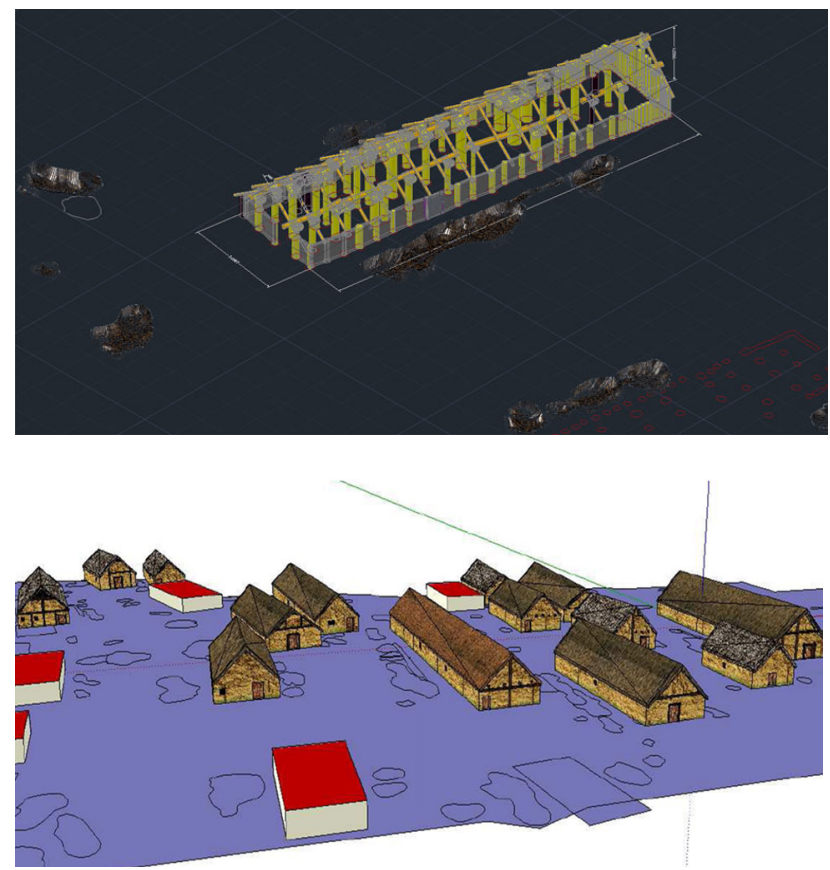

Figure 4: Samples of various types of 3D reconstructions (Authors: P. VavreČka, Č. Kraciv). dels (objects built on the basis of archaeological records and factual reconstruction, Figure 4) and computer views (a kind of scenic reconstruction, Figure 5). The reconstructions will be created also with the software package Autodesk and Google SketchUp. The result will be not only static images, but also dynamic presentations accessible either in the form of interactive cooperation user-application or animation with narrative attributes.

\section{DISCUSSION/CONCLUSION/FUTURE WORK}

The default solution will be the project which was completed in 2007 called "Neolithic settlement in Bylany - essential database". The documentation of the results of the archaeological research in Bylany was transformed into the form of a compact line-up which includes database, image documentation and a GIS map. It was published as a whole both in the printed form as a digital part of a metadata handbook and on the Internet in the domain, www.bylany.com. (KvČtina and PavlČ, 2007). The current project is advancing in accordance with a time schedule and with the digitising laboratory work having started earlier this year, to date, 250 artefacts (70 of them are vessels) have been scanned. During the following years (2013-2015), we assume the creation of optimised database of 3D models of artefacts of the following categories: complete ceramic vessels (at least 200 pieces), ceramic fragments (at least 300 pieces), polished stones (at least 500 pieces), chipped stones (at least 500 pieces) and grinding stones (at least 50 pieces). At the same time the corresponding software default for depositing and inspection of 3D models of artefacts will be created as well as a special GIS map for the Internet application.

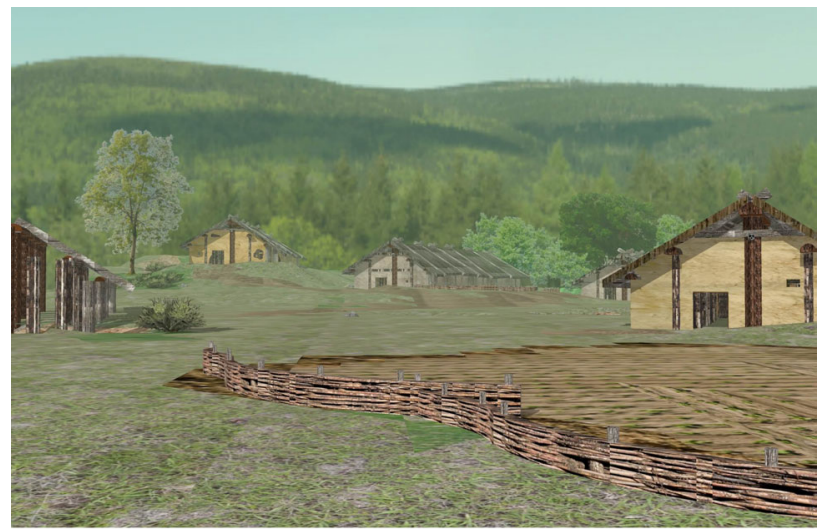

Figure 5: Sample of scenic reconstruction of a Neolithic settlement. (Author: P. VavreČka).

\section{ACKNOWLEDGEMENTS}

The financial support of this project was provided by the Ministry of Culture of the Czech Republic as a part of the projected Programme of applied research and development of national and cultural identity called "Archaeological 3D virtual museum. New technologies in documentation and presentation of Neolithic settlement" (Project No. DF12P01OVV032). We would like to thank to John Novotney for English revision of the manuscript. 


\section{REFERENCES}

Archer, W., Braun, D. R., 2010. Variability in bifacial technology at Elandsfontein, Western cape, South Africa: a geometric morphometric approach. Journal of Archaeological Science, 37, pp. 201-209.

Bruno, F., Bruno, S., De Sensi, G., (et al.) 2010. From 3D reconstruction to virtual reality: A complete methodology for digital archaeological exhibition. Journal of Cultural Heritage, 11, pp. 42-49.

Buchanan, B., Collard, M., 2010. A geometric morphometricsbased assessment of blade shape differences among Paleoindian projectile point types from western North America. Journal of Archaeological Science, 37, pp. 350-359.

Gilboa, A., Karasik, A., Sharon, I., (et al.) 2004: Towards computerized typology and classification of ceramics. Journal of Archaeological Science. 31, pp. 681-694.

Grant, J., Gorin, S., Fleming, N., 2008. The Archaeology Coursebook. An Introduction to Themes, Sites, Methods and Skills, 3rd Edition, Routledge, New York.
KvČtina, P., PavlČ , I.,2007. Neolitické sídliČtČ v Bylanechzákladní databáze. Neolithic settlement at Bylany - essential database. Institute of Archaeology, Prague.

Lycett, S. J., von Cramon-Taubadel, N., Gowlett, J. A. J., 2010. A comparative 3D geometric morphometric analysis of Victoria West cores: implications for the origins of Levallois technology. Journal of Archaeological Science, 37, pp.1110-1117.

Saragusti, I., Karasik, A., Sharon, I., (et al. 2005). Quantitative analysis of shape attributes based on contours and section profiles in artifact analysis. Journal of Archaeological Science, 32, pp. 841-853.

Urbanová, P., Králík, M., 2009. Kvantitativni popis tvaru pomoci metod geometrické morfometrie. In: Malina, J. Svoboda, J. (eds.) Čas lovcČ: Aktualizované dČjiny paleolitu. Panoráma antropologie: biologické - sociální - kulturní. Masarykova univerzita, Brno, pp. 277-289. 